\title{
The roles of TNF- $\alpha$ and the soluble TNF receptor I on sleep architecture in OSA
}

\author{
Herbert J. Yue • Paul J. Mills • Sonia Ancoli-Israel • \\ José S. Loredo • Michael G. Ziegler • Joel E. Dimsdale
}

Received: 10 March 2008 /Revised: 3 December 2008 / Accepted: 16 December 2008 / Published online: 16 January 2009

(C) The Author(s) 2009. This article is published with open access at Springerlink.com

\begin{abstract}
Objective Patients with obstructive sleep apnea (OSA) have been described to have increased levels of inflammatory cytokines (particularly TNF- $\alpha$ ) and have severely disturbed sleep architecture. Serum inflammatory markers, even in normal individuals, have been associated with abnormal sleep architecture. Not much is known about the role the TNF receptor plays in the inflammation of OSA nor if it is associated with changes in sleep architecture or arousals during the night. We hypothesized that the TNF receptor might play an important role in the inflammation as well as sleep architecture changes in patients with OSA.

Design Thirty-six patients with diagnosed (AHI $>15)$ but untreated OSA were enrolled in this study. Baseline polysomnograms as well as TNF- $\alpha$ and soluble TNF receptor I (sTNF-RI) serum levels were obtained on all patients. We evaluated the association between serum levels of TNF- $\alpha$ and sTNF-RI with various polysomongraphic characteristics, including sleep stages and EEG arousals. Results sTNF-RI levels were significantly correlated with snore arousals ( $r$ value $0.449, p$ value 0.009 ), spontaneous movement arousals ( $r$ value $0.378, p$ value 0.025$)$, and periodic limb movement arousals $(r$ value $0.460, p$ value 0.008 ). No statistically significant correlations were observed with TNF- $\alpha$ to any polysomnographic variables. To control for statistical significance with multiple compar-
\end{abstract}

H. J. Yue $(\bowtie) \cdot J$. S. Loredo $\cdot$ M. G. Ziegler

Department of Medicine, University of California,

San Diego School of Medicine,

La Jolla, CA, USA

e-mail: hyue@ucsd.edu

P. J. Mills $\cdot$ S. Ancoli-Israel $\cdot$ J. E. Dimsdale

Department of Psychiatry, University of California,

San Diego School of Medicine,

La Jolla, CA, USA isons, a MANOVA was performed with TNF- $\alpha$ and STNF$\mathrm{RI}$ as dependent variables and sleep architecture measures and arousals as independent variables. The model for sTNF-RI was statistically significant $(F$ value $2.604, p$ value 0.03 ), whereas the model for TNF- $\alpha$ was not, suggesting sleep quality significantly affects sTNF-RI. Hierarchal linear regression analysis demonstrated that sTNF-RI was independently associated with spontaneous movement arousal index scores after controlling for age, body mass index, and sleep apnea severity.

Conclusions These findings suggest that sTNF-RI is associated with arousals during sleep, but not with other measures in patients with OSA.

Keywords Obstructive sleep apnea - Inflammation . Sleep architecture - Arousals · Tumor necrosis factor . Soluble TNF receptor

\section{Introduction}

Obstructive sleep apnea (OSA) is a common condition characterized by repeated episodes of upper airway obstruction which result in interruptions of breathing during sleep, recurring episodes of hypoxemia, sleep fragmentation, and daytime sleepiness. OSA is found in approximately $5 \%$ of the general population and is a significant source of morbidity and mortality [1]. The full pathogenesis of obstructive sleep apnea is not clear; recent literature suggest that in addition to mechanical factors in the airway, there may be an inflammatory etiology.

Surgical biopsies of the uvula in patients with OSA have demonstrated histological abnormalities, including subepithelial edema and excessive inflammatory cell infiltration [2-3]. Mediators of the systemic inflammatory response, 
including cell adhesion molecules (ICAM), coagulation factors (Factor VIII, Tissue factor), C-reactive protein (CRP), and pro-inflammatory cytokines are also up-regulated in patients with OSA [4-6]. In particular, significant elevations in serum levels of TNF- $\alpha$, IL-1 $\beta$, and IL-6 have been seen in patients with obstructive sleep apnea [7-11].

TNF- $\alpha$ has been one of the more closely studied cytokines in the pathogenesis of OSA. Physiologically, $\mathrm{TNF}-\alpha$ is a pro-inflammatory cytokine with a significant role in host defense and mediates the pathogenesis of a number of disease processes, including septic shock, atherosclerosis, and auto-immune disease [12]. TNF- $\alpha$ has two transmembrane-bound receptors (p55 TNF-RI and p75 TNF-RII) as well as soluble forms (sTNF-RI and sTNF-RII) that are released by proteolysis of the cell-bound receptor under the control of inflammatory cytokines (e.g., IL-6, IL-2, IFN- $\gamma$ ), T cell activation, and by TNF- $\alpha$ itself [12-13].

In patients with untreated OSA, elevations in TNF- $\alpha$ are observed [7-10]. When given continuous positive airway pressure treatment (CPAP), subjects are noted to have significant decreases in circulating TNF- $\alpha$ [8]. Despite the large body of investigation regarding the role of TNF- $\alpha$ in the pathogenesis of OSA, not much is known about any role the TNF-R receptor plays. In models of cardiopulmonary bypass and trauma, increased levels of soluble TNF-R are noted [14-15]. Elevated levels of TNF-R are considered markers of an inflammatory response, although they may themselves act in an anti-inflammatory manner by binding excess ligand [12]. sTNF-RI is the predominant form shed from pulmonary epithelial cells in pulmonary disease and has been studied as a potential inflammatory mediator in models of acute lung injury [15-18]. Serum levels of p55 TNF-R have been noted to be associated with morbidity, mortality, and patient outcomes in patients with acute lung injury [17-20]. Elevated levels of sTNF-RI have not been consistently described in patients with OSA and it is not known if these levels contribute additional information about the inflammation seen in OSA.

The role of cytokines in disrupting the architecture of sleep is also in need of further study. Serum inflammatory markers, even in normal individuals, have been associated with abnormal sleep architecture [21]. In subjects with increased levels of TNF- $\alpha$ associated with HIV, increases in EEG delta amplitude have been seen on polysomnograms [22]. There has been interest in EEG arousals, as these may be a potential stimulus for the sympathetic nervous system activation seen in OSA [23-25]. EEG arousals are globally defined as abrupt changes in EEG frequency to alpha without spindle activity. They can be measured in a variety of different ways and can be divided into cortical, movement, and respiratory arousals. There has been limited investigation into the role and utility of sub-classifying arousals, although we have previously shown that move- ment arousals can influence daytime sympathetic tone [25]. There is limited data regarding any association between EEG arousals and inflammation in patients with OSA and it is not clear if the two are related.

Given the limited data on the role of TNF-R in OSA, this study investigated the association between TNF- $\alpha$ and sTNF-RI with sleep architecture measures, including arousals. In addition, the association between these inflammatory cytokines and the severity of obstructive sleep apnea was also examined.

\section{Materials and methods}

Patients Subjects suspected of having obstructive sleep apnea were recruited. Thirty-six (28 men and eight women) were found to have obstructive sleep apnea $(\mathrm{AHI}>15)$ by polysomnogram and were invited to participate in the protocol. None of the subjects had previously been treated for sleep apnea. Participants completed a physical examination and answered questions about their medical history to determine eligibility for the study. Participants were excluded if they had a history of a major illness such as heart disease, liver or kidney disease, asthma, stroke, or other neurologic disorders. Women were also excluded if pregnant. Basic intake data were obtained on all participants, including age, ethnicity, vital signs, weight and BMI, education, and occupation. The study was approved by the Institutional Review Board at the University of California, San Diego (UCSD) and participants were studied after obtaining written informed consent.

TNF assays Blood was drawn via saline lock previously inserted at approximately 6 AM the following morning after the polysomnogram was obtained. Following centrifugation, serum was stored at $-80^{\circ} \mathrm{C}$ until assayed. Levels of TNF- $\alpha$ and sTNF-RI were measured on non-freeze-thawed samples with an enzyme-linked immunosorbent assay (R\&D Systems, Minneapolis, MN, USA). The precision and sensitivity performance values for TNF- $\alpha$ were an intra-assay coefficient of variation of $5.3 \%$, inter-assay coefficient of variation of $8.4 \%$, and sensitivity of $0.106 \mathrm{pg} / \mathrm{mL}$. For the sTNF-RI measurements, the precision and sensitivity performance values for sTNF-RI were an intra-assay coefficient of variation of $4.4 \%$ with an, inter-assay coefficient of variation of $6.1 \%$, and mean sensitivity of $0.77 \mathrm{pg} / \mathrm{mL}$.

Polysomnography Standard overnight polysomnography on one night was performed on all participants on the Gillin Laboratory of Sleep and Chronobiology of the UCSD General Clinical Research Center. Polysomnography procedures have been previously described [25]. Briefly, electroencephalography, electroculography, chin electromy- 
ography, and thoracic and abdominal respiratory effort were recorded on a Grass Heritage digital polysomnograph (Model PSG36-2, Astro-Med, Inc, West Warwick, RI). Oxygen saturation was measured with a pulse oximeter (Biox 3740; Ohmeda: Louisville, Colorado). Sleep recordings were scored in 30-s epochs and staged according to the criteria of Rechtshaffen and Kales [26]. The following sleep variables were computed: \% of each stage of sleep $(1,2$, slow wave sleep), oxygen desaturation index (ODI), and apnea hypopnea index (AHI). Oxygen desaturations were defined as $a \geq 3 \%$ decrease in oxyhemoglobin saturation from baseline; the number of events was divided by the total sleep time in hours to obtain the ODI. Apneas and hypopneas were defined as decrements in airflow of $<90 \%$ and $>50 \%$ from baseline lasting at least $10 \mathrm{~s}$ respectively. Air flow was measured with a nasal pressure transducer via nasal cannula as well as with a thermistor. Apneas and hypopneas were scored using the nasal pressure transducer primarily. The thermistor was used as a secondary measurement to determine oral breathing and as a back up measure. Apneas and hypopneas were defined on the basis of decrement in airflow alone. The number of apneas and hypopneas per hour of sleep were calculated to obtain the AHI. Arousals were scored according to the general criteria of the ASDA [27] and globally defined as sudden increases in EEG frequency to alpha or theta without spindle activity, lasting at least $3 \mathrm{~s}$ but less than $15 \mathrm{~s}$, with at least $10 \mathrm{~s}$ of sleep recorded prior to the arousal. Arousals were then further sub-classified as previously described [28]:

1. Snore arousal: any type of arousal occurring immediately following a period of crescendo snoring in the absence of an apneic event. Snore arousals include respiratory effort-related arousals.

2. Periodic limb movement arousal: sudden increase in EEG frequency following a periodic limb movement in the absence of an apneic event or crescendo snoring.

3. Respiratory cortical arousal: sudden increase in EEG frequency without obvious rise in EMG activity occurring within three breaths after the termination of a respiratory apneic event.

4. Respiratory movement arousal: sudden increase in EEG frequency associated with increased in EMG activity of the chin or of the tibialis anterior muscle occurring within three breaths after the termination of a respiratory apneic event.

5. Spontaneous cortical arousal: sudden increase in EEG frequency without an increase in EMG activity occurring in the absence of an obvious precipitating event.

3. Spontaneous movement arousal: sudden increase in EEG frequency associated with an increase in EMG activity of the chin or of the tibialis anterior muscle, occurring in the absence of an obvious precipitating event.
Indices for each arousal type were calculated by summing the number of each particular arousal and dividing by the total sleep time.

Statistical analyses Descriptive statistics were used to determine mean values for demographic and anthropometric characteristics, sleep architecture, and cytokine levels in the study sample population. Pearson correlations were performed between TNF- $\alpha$ and sTNF-RI levels and the various polysomnographic measures. We also performed a multivariate ANOVA using TNF- $\alpha$ and sTNF-RI as dependent variables with sleep parameters and arousals as covariates to evaluate for statistical significance in the context of multiple comparisons. Hierarchal linear regression analysis was then performed to evaluate if various demographic parameters or sleep apnea severity had any effects on the cytokine-sleep architecture relationships. Statistics were considered significant at $p<0.05$. Statistical analyses were performed using SPSS statistical software (SPSS for Windows 12.0: SPSS Inc.; Chicago).

\section{Results}

A total of 36 patients with obstructive sleep apnea completed the study. Table 1 describes the subjects' demographic and anthropometric characteristics. Patients were on average 46 years old ( \pm 10 years), predominantly male, and mildly obese $\left(\mathrm{BMI}=31.2 \pm 5.3 \mathrm{~kg} / \mathrm{m}^{2}\right)$. Table 2 depicts the sleep parameters. On average, the sample population had severe OSA $(\mathrm{AHI}=64.9 \pm 33.1)$. The mean total arousal index was severely elevated at $46.7 \pm 32.8$, and the majority were respiratory movement arousals. The oxygen desaturation index (ODI) was also elevated at $42.7 \pm 36.7$ desaturation events per hour. The percent of stage 1 and 2 sleep were elevated at $17.8 \%$ and $61.0 \%$, respectively. The percent of slow wave sleep and REM sleep were both low at $5.7 \%$ and $15.5 \%$. Average TNF- $\alpha$ levels were $1.96 \pm 2.11 \mathrm{pg} / \mathrm{mL}$; average sTNF-RI levels were $956.3 \pm 184.8 \mathrm{pg} / \mathrm{mL}$.

Table 3 summarizes the Pearson correlation analysis. Correlation analyses between TNF- $\alpha$ and measures of apnea severity, desaturation indices, and sleep architecture did not show any statistically significant associations. There

Table 1 Clinical characteristics

\begin{tabular}{lc}
\hline Characteristic & Mean $\pm \mathrm{SD}$ \\
\hline Age, years & $46.5 \pm 10.3$ \\
Gender & 28 male, \\
& 8 female \\
BMI, $\mathrm{kg} / \mathrm{m}^{2}$ & $31.2 \pm 5.3$ \\
\hline
\end{tabular}


Table 2 Sleep characteristics

\begin{tabular}{lc}
\hline Sleep recording measures & Mean \pm SD (range) \\
\hline \% Stage 1 sleep & $17.8 \pm 9.6(3.5-46)$ \\
$\%$ Stage 2 sleep & $61.0 \pm 9.9(39.5-77.7)$ \\
$\%$ Slow wave sleep (stage 3 and 4) & $5.7 \pm 7.5(0-26.7)$ \\
$\%$ REM Sleep & $15.5 \pm 6.2(4.2-30.2)$ \\
AHI & $64.9 \pm 33.1(16.2-135.9)$ \\
AI & $36.0 \pm 35.2(0.2-117.4)$ \\
ODI & $42.7 \pm 36.7(0-125.9)$ \\
Total arousal index & $46.7 \pm 32.7(8.2-122.7)$ \\
Snore arousal index & $2.0 \pm 2.2(0-8.8)$ \\
Spontaneous cortical arousal index & $1.0 \pm 1.2(0-5.4)$ \\
Respiratory cortical arousal index & $2.8 \pm 5.1(0-30.3)$ \\
Spontaneous movement arousal index & $1.5 \pm 1.3(0-4.9)$ \\
Respiratory movement arousal index & $38.9 \pm 35.3(1.4-120.5)$ \\
Periodic limb movement index & $0.4 \pm 0.8(0-3.5)$
\end{tabular}

were, however, a number of statistically significant associations observed between sTNF-RI and arousal indices, including snore arousals ( $r$ value $0.449, p$ value 0.009 ), periodic limb movement arousals ( $r$ value $0.460, p$ value 0.008 ), and spontaneous movement arousals ( $r$ value 0.378 , $p$ value 0.025$)$. To control for multiple comparisons, we used a MANOVA model with TNF- $\alpha$ and sTNF-RI as dependent variables and using arousals and sleep architecture variables as covariates. The model for TNF- $\alpha$ was not significant ( $F$ value $0.563, p$ value 0.788 ), but the model for sTNF-RI was statistically significant ( $F$ value $3.12, p$ value 0.02; Figs. 1, 2, and 3).

Based on the observed significant univariate associations with sTNF-RI, we then analyzed the data with hierarchal linear regression to determine if arousal indices contributed additional independent information to levels of sTNF-RI,

Table 3 Univariate correlations

\begin{tabular}{lll}
\hline & TNF- $\alpha$ & sTNF-RI \\
\hline \% light sleep (stage S1) & 0.174 & 0.053 \\
\% light sleep (stage S2) & 0.182 & 0.093 \\
\% deep sleep (stage S3 + S4) & 0.275 & 0.124 \\
\% REM Sleep & 0.226 & 0.083 \\
AHI & 0.126 & 0.169 \\
AI & 0.180 & 0.301 \\
ODI & 0.051 & 0.265 \\
Total arousal index & 0.052 & 0.170 \\
Snore arousal index & 0.033 & $0.449^{* *}$ \\
Spont cortical arousal index & 0.080 & $0.220^{*}$ \\
Resp cortical arousal index & 0.076 & 0.072 \\
Spont movement arousal index & 0.329 & $0.378^{* *}$ \\
Resp movement arousal index & 0.062 & 0.224 \\
Periodic limb movement arousal index & 0.138 & $0.460^{* *}$ \\
\hline
\end{tabular}

$R$ values are listed below $(n=36)$

${ }^{*} p<0.05, * * p<0.01$

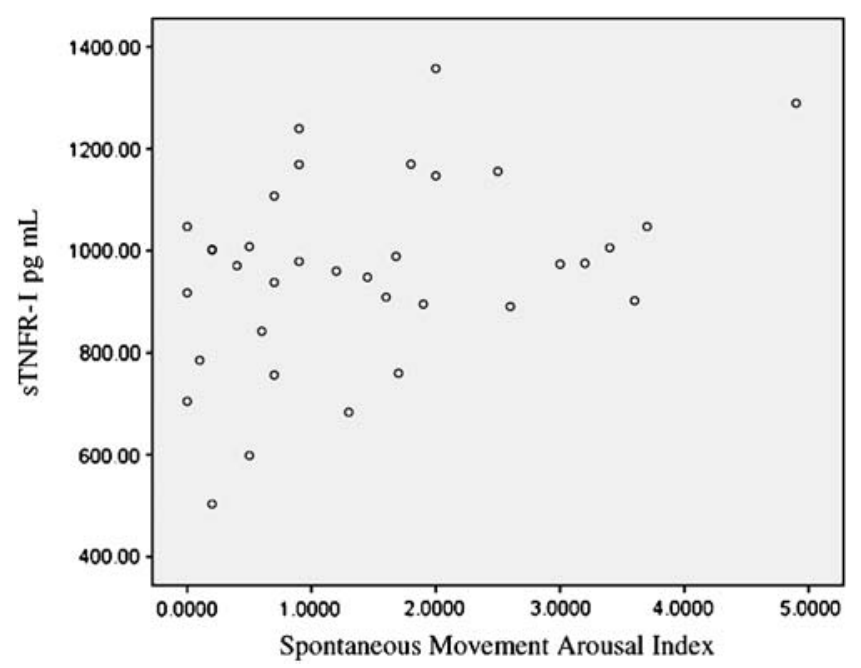

Fig. 1 Scattergrams of sTNFR-I with the spontaneous movement arousal index

after controlling for demographic variables and sleep apnea severity. sTNF-RI levels were the dependent variable. At step 1, we forced entry of age and BMI. For step 2, we entered AHI and the oxygen desaturation index. For step 3, we entered the appropriate arousal index, based on indices with significant Pearson correlations. Detailed regression results for spontaneous movement arousals are shown in Table 4. A summary of the regression analyses for the other arousals indices is shown in Table 5.

For the periodic limb movement index and snore arousal index, neither final model was statistically significant, and the arousals did not contribute significantly to the variance of sTNF-RI levels. For the spontaneous movement index, the overall model was significant $(p=0.045)$ and spontaneous movement arousals accounted for a significant proportion of the variance of sTNF-RI levels $\left(R^{2}\right.$ change 0.147 ,

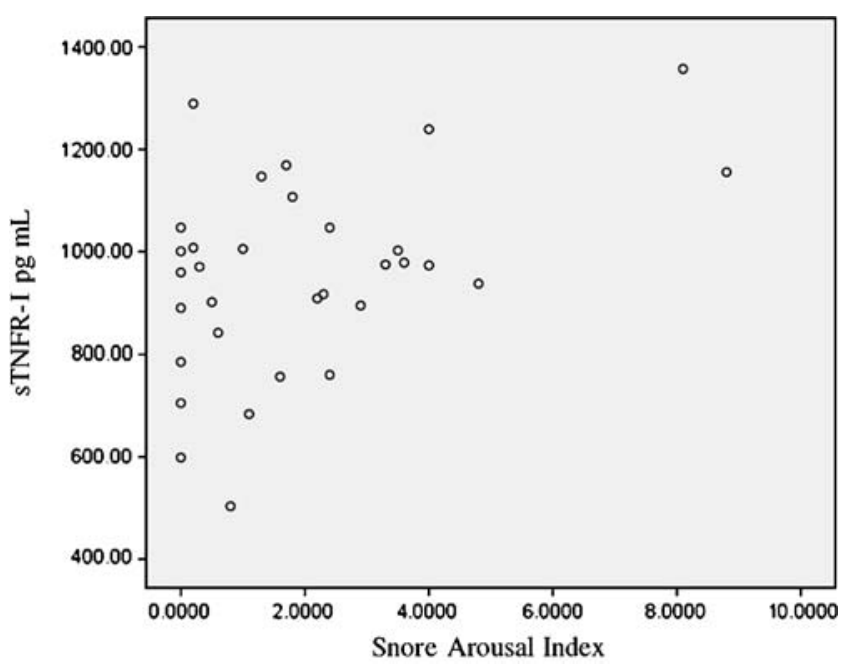

Fig. 2 Scattergrams of sTNFR-I with the snore arousal index 


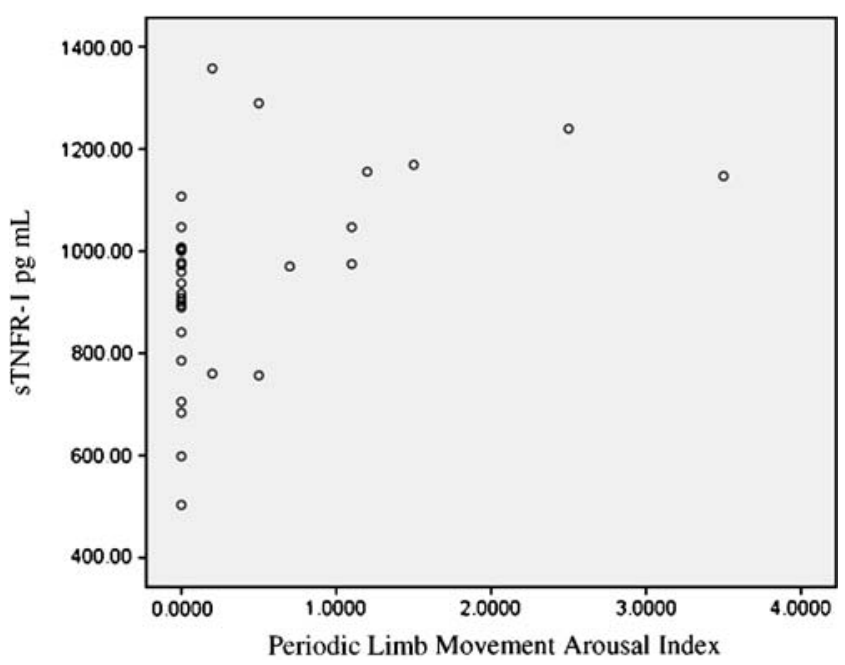

Fig. 3 Scattergrams of sTNFR-I with the periodic limb movement index

$p=0.021)$. None of the demographic or sleep apnea severity characteristics contributed significantly towards sTNF-RI levels.

\section{Discussion}

This study sought to investigate the role of the soluble TNF receptor I and TNF- $\alpha$ in obstructive sleep apnea and their relationship to measures of sleep architecture and arousals. A central finding of this study was that levels of sTNF-RI in patients with OSA were positively associated with arousals, whereas TNF- $\alpha$ levels were not associated with any sleep apnea severity or sleep architecture measures.

Table 4 Multiple regression predictors of sTNFR-I and spontaneous movement arousal index

\begin{tabular}{|c|c|c|c|c|c|c|}
\hline & $R$ & $R^{2}$ & $\begin{array}{l}\text { Adjusted } \\
R^{2}\end{array}$ & Variables & $\beta$ & $P$ value \\
\hline \multirow[t]{2}{*}{ Step $1^{\mathrm{a}}$} & 0.256 & 0.065 & 0.001 & Age & 0.266 & 0.172 \\
\hline & & & & BMI & 0.039 & 0.837 \\
\hline \multirow[t]{4}{*}{ Step $2^{\mathrm{b}}$} & 0.430 & 0.184 & 0.064 & Age & 0.136 & 0.491 \\
\hline & & & & BMI & 0.304 & 0.236 \\
\hline & & & & AHI & -0.055 & 0.833 \\
\hline & & & & ODI & 0.440 & 0.090 \\
\hline \multirow[t]{5}{*}{ Step $3^{c}$} & 0.582 & 0.339 & 0.211 & Age & -0.009 & 0.962 \\
\hline & & & & BMI & 0.343 & 0.150 \\
\hline & & & & AHI & -0.073 & 0.761 \\
\hline & & & & ODI & 0.423 & 0.077 \\
\hline & & & & $\begin{array}{l}\text { Spontaneous } \\
\text { movement } \\
\text { arousal }\end{array}$ & 0.425 & 0.021 \\
\hline
\end{tabular}

${ }^{\mathrm{a}} F(2,32)=1.013, p=0.375, R^{2}$ change 0.001

${ }^{\mathrm{b}} F(4,30)=1.527, p=0.222, R^{2}$ change 0.053

${ }^{\mathrm{c}} F(5,29)=2.661, p=0.045, R^{2}$ change 0.147
Table 5 Multiple regression predictors of sTNFR-I and snore and periodic limb movement arousal indices

\begin{tabular}{lll}
\hline $\begin{array}{l}\text { Dependent } \\
\text { variable }\end{array}$ & $\begin{array}{l}\text { Significant individual predictor } \\
\text { variables with } \beta \text { coefficients; } \\
p \text { values }\end{array}$ & $\begin{array}{l}\text { Model unadjusted } R^{2} ; \\
\text { adjusted } R^{2 \mathrm{a}} ; p \text { value }\end{array}$ \\
\hline sTNFR-I & $\begin{array}{c}\text { Snore arousal index } \\
(0.340 ; 0.082)\end{array}$ & $0.273 ; 0.136 ; p=0.116$ \\
sTNFR-I & $\begin{array}{c}\text { Periodic limb movement } \\
\text { arousal index }(-0.083 ; 0.674)\end{array}$ & $0.156 ; 0.010 ; p=0.396$ \\
\hline
\end{tabular}

${ }^{\text {a }}$ Adjusted $R^{2}$ is the $R^{2}$ adjusted for number of predictors in the model and sample size

This association of sTNF-RI with arousals is intriguing. Soluble forms of the TNF receptor are up-regulated in states of increased TNF- $\alpha$ levels [12]. In particular, the RI form of the TNF receptor has been shown to regulate sleep in animals [29]. A study of total sleep deprivation in normal volunteers noted increased levels of sTNF-RI (but not TNF$\alpha)$ that correlated with levels of sleep deprivation [30]. The RI form of the soluble TNF receptor is the predominant form shed from pulmonary epithelial cells and suggests a role as a modulator of the inflammation in OSA, potentially via the frequent hypoxemic episodes seen in these patients. Our hierarchical linear regressions noted incremental information provided by STNF-RI that were not seen with the TNF- $\alpha$ data alone, particularly with spontaneous movement arousals.

Potential limitations of our study include the overall sample size and our method of subdividing arousals in different types. Although we did not necessarily expect a differential effect on sTNF-RI levels by different types of arousals, we have found some benefit in examining specific types of arousals. For instance, prior work done by our group has shown that sympathetic nervous system activation was predominantly affected by movement arousals and not cortical arousals [25]. We believe our results are interesting initial observations in the role of arousals in the contribution to the inflammation seen in OSA. These results also suggest that not all types of arousals equally contribute to elevations in cytokine levels.

As previously mentioned, we did not see any significant correlations of TNF- $\alpha$ with any measures of apnea severity or changes in sleep architecture. Other studies have previously noted significant correlations of TNF- $\alpha$ with measures of apnea severity and oxygen desaturation [8], although the literature is inconsistent [33]. There are a number of potential reasons for this; assay sensitivity potentially plays a role. The majority of the literature uses an ultra-sensitive Bioscience TNF- $\alpha$ assay, whereas a R\&D TNF- $\alpha$ assay was used in this study; however, mean sensitivity and minimum detectable doses are comparable across the two assays. Other potential reasons include the 
method in which we measured TNF- $\alpha$. TNF- $\alpha$ can be found free or bound to its receptor (soluble and/or cellbound). Although our TNF- $\alpha$ assay measured both free- and receptor-bound ligand, we only analyzed cell free samples and did not measure the amount of receptor-bound ligand still attached to the cell membrane when preparing the serum and may have potentially decreased the total amount of TNF- $\alpha$ measured. Sampling time is also a potential confounder, as TNF- $\alpha$ exhibits a diurnal variation in normal patients and different sampling times could explain some of the variation in TNF- $\alpha$ levels. Most studies including this present one, however, drew serum samples in the early morning. There is also no widely accepted standard range of TNF- $\alpha$ levels in apneics. Our review of the literature yields ranges from $0.98 \mathrm{pg} / \mathrm{mL}$ up to $7 \mathrm{pg} / \mathrm{mL}$ and higher [7-11, 31-35]. Our average TNF- $\alpha$ level was $1.96 \mathrm{pg} / \mathrm{mL}$, which was not significantly different from previously reported values. Our failure to observe significant associations between TNF- $\alpha$ and sleep may also relate to sample size, but none of the correlations of TNF- $\alpha$ with any sleep variables approached any statistical significance.

The lack of any significant correlations of TNF- $\alpha$ to any measures of apnea severity or sleep fragmentation may also be related to the interplay of TNF- $\alpha$ and its soluble receptor, as the receptor may have downregulated the activity of TNF- $\alpha$, limiting its utility in evaluating associations with sleep architecture changes and arousals. Similar results have been noted in the acute lung injury literature where the soluble receptor has been shown to have associations with disease severity as well as prognostic information, whereas no significant findings were observed with TNF- $\alpha$. Despite the lack of associations of TNF- $\alpha$ with sleep variables however, it is important to note there is literature demonstrating that at least TNF- $\alpha$ levels in the brain are important to sleep regulation [36].

This study was limited to patients with OSA. Given the nature of our study design, it is unknown if these results apply to healthy control subjects or to sleep disorder patient populations who do not suffer from OSA. We felt, however, that the design of our study was a legitimate first step in the evaluation of the role of sTNF-RI in OSA. The natural next step would be to replicate these findings as well as evaluate if they are also found in other sleep disorders. In particular, patients with upper airway resistance syndrome (characterized by frequent arousals but without apneic episodes) would be an interesting population to study further.

In summary, our data suggest an association between soluble TNF receptor I and EEG arousals in obstructive sleep apnea. The data also suggest that movement arousals may be an independent predictor of levels of sTNF-RI. In conclusion, our data suggest that disrupted sleep quality in obstructive sleep apneics may be playing contributing to the systemic inflammation seen in these patients.
Acknowledgments This work was supported by grants HL44915 and M01 RR00827, AG08415, and CA112035 from the National Institutes of Health. Address correspondence to Dr. Yue at UC San Diego Medical Center, Dept Pulm/Crit Care Medicine, 200 West Arbor Drive, San Diego, CA 92103-8383.

Open Access This article is distributed under the terms of the Creative Commons Attribution Noncommercial License which permits any noncommercial use, distribution, and reproduction in any medium, provided the original author(s) and source are credited.

\section{References}

1. Young T, Skatrud J, Peppard PE (2004) Risk factors for obstructive sleep apnea in adults. JAMA 291:2013-2016. doi:10.1001/jama.291.16.2013

2. Sekosan M, Zakkar M, Wenig BL, Olopade CO, Rubenstein I (1996) Inflammation in the uvula mucosa of patients with obstructive sleep apnea. Laryngoscope 106:1018-1020. doi:10.1097/00005537-199608000-00021

3. Bergeron C, Kimoff J, Hamid Q (2005) Images in allergy and immunology: obstructive sleep apnea syndrome and inflammation. J Allergy Clin Immunol 116:1393-1396. doi:10.1016/j. jaci.2005.10.008

4. Ursavaş A, Karadağ M, Rodoplu E, Yilmaztepe A, Oral HB, Gözü RO (2007) Circulating ICAM-1 and VCAM-1 levels in patients with obstructive sleep apnea syndrome. Respiration 74:525-532. doi:10.1159/000097770

5. von Känel R, Loredo JS, Ancoli-Israel S, Mills PJ, Natarajan L, Dimsdale JE (2007) Association between polysomnographic measures of disrupted sleep and prothrombotic factors. Chest 131:733-739. doi:10.1378/chest.06-2006

6. Punjabi NM, Beamer BA (2007) C-reactive protein is associated with sleep disordered breathing independent of adiposity. Sleep 30:29-34

7. de la Pena Bravo M, Serpero LD, Barcelo A et al (2007) Inflammatory proteins in patients with obstructive sleep apnea with and without daytime sleepiness. Sleep Breath 11:177-185. doi:10.1007/s11325-007-0100-7

8. Minoguchi K, Tazaki T, Yokoe T et al (2004) Elevated production of tumor necrosis factor- $\alpha$ by monocytes in patients with obstructive sleep apnea syndrome. Chest 126:1473-1479. doi:10.1378/ chest.126.5.1473

9. Ciftci TU, Korturk O, Bukan N et al (2004) The relationship between serum cytokine levels with obesity and obstructive sleep apnea syndrome. Cytokine 28:87-91. doi:10.1016/j.cyto.2004.07.003

10. Vgontzas AN, Papanicolaou DA, Bixler EO, Kales A, Tyson K, Chrousos GP (1997) Elevation of plasma cytokines in disorders of excessive daytime sleepiness: role of sleep disturbance and obesity. J Clin Endocrinol Metab 82:1313-1316. doi:10.1210/jc.82.5.1313

11. Vgontzas AN, Papanicolaou DA, Bixler EO, Hopper K, Lotsikas A, Lin HM, Kales A, Chrousos GP (2000) Sleep apnea and daytime sleepiness and fatigue: relation to visceral obesity, insulin resistance, and hypercytokinemia. J Endocrinol Metab 85:1151-1158. doi:10.1210/jc.85.3.1151

12. Aderka D (1996) The potential biological and clinical significance of the soluble tumor necrosis factor receptors. Cytokine Growth Factor Rev 7:231-240. doi:10.1016/S1359-6101(96)00026-3

13. Brockhaus M, Schoenfeld H, Schlaeger E, Hunziker W, Lesslauer W, Loetscher H (1990) Identification of two types of tumor necrosis factor receptors on human cell lines by monoclonal antibodies. Proc Natl Acad Sci USA 87:3127-3131. doi:10.1073/pnas.87.8.3127 
14. ElBarbary MKKS, ElBarbary M, Khabar K (2002) Soluble tumor necrosis factor receptor $\mathrm{p} 55$ predicts cytokinemia and systemic inflammatory response after cardiopulmonary bypass. Crit Care Med 30:1712-1716. doi:10.1097/00003246-200208000-00006

15. Hensler T, Sauerland S, Bouillion B, Raum M, Rixen D, Helling H, Andermahr J, Neugebauer E (2002) Association between injury pattern of patients with multiple injuries and circulating levels of soluble tumor necrosis factor receptors, interleukin-6 and interleukin-10, and polymorphonuclear neutrophil elastase. J Trauma 52:962-970. doi:10.1097/00005373-200205000-00023

16. Pittet J, Mackersie R, Martin T, Matthay M (1997) Biological markers of acute lung injury: prognostic and pathogenetic significance. Am J Respir Crit Care Med 155:1187-1205

17. Parsons PE, Matthay MA, Ware LB, Eisner MD, National Heart, Lung, Blood Institute Acute Respiratory Distress Syndrome Clinical Trials Network (2005) Elevated plasma levels of soluble TNF receptors are associated with morbidity and mortality in patients with acute lung injury. Am J Physiol Lung Cell Mol Physiol 288:L426-L431. doi:10.1152/ajplung.00302.2004

18. Ranieri VM, Suter PM, Tortorella C, De Tullio R, Dayer JM, Brienza A, Bruno F, Slutsky AS (1999) Effect of mechanical ventilation on inflammatory mediators in patients with acute respiratory distress syndrome: a randomized controlled trial. JAMA 282:54-61. doi:10.1001/jama.282.1.54

19. Hyers T, Tricomi SM, Dettenmeier P, Fowler A (1991) Tumor necrosis factor levels in serum and bronchoalveolar lavage fluid of patients with the adult respiratory distress syndrome. Am Rev Respir Dis 144:268-271

20. Parsons P, Moore F, Moore E, Ikle D, Henson P, Worthen G (1992) Studies on the role of tumor necrosis factor in adult respiratory distress syndrome. Am Rev Respir Dis 146:694-700

21. Mills PJ, von Känel R, Norman D, Natarajan L, Ziegler MG, Dimsdale JE (2007) Inflammation and sleep in healthy individuals. Sleep 30:729-735

22. Darko DF, Miller JC, Gallen C, White J, Koziol J, Brown SJ, Hayduk R, Atkinson JH, Assmus J, Munnell DT, Naitoh P, McCutchan JA, Mitler MM (1995) Sleep electroencephalogram delta-frequency amplitude, night plasma levels of tumor necrosis factor alpha, and human immunodeficiency virus infection. Proc Natl Acad Sci USA 92:12080-12084. doi:10.1073/pnas.92.26.12080

23. Somers VK, Dyken ME, Clary MP, Abboud FM (1995) Sympathetic neural mechanisms in obstructive sleep apnea. J Clin Invest 96:1897-1904. doi:10.1172/JCI118235

24. Narkiewica K, van de Borne PJ, Cooley RL, Dyken ME, Somers VK (1998) Sympathetic activity in obese subjects with and without obstructive sleep apnea. Circulation 98:772-776
25. Loredo JS, Ziegler MG, Ancoli-Israel S, Clausen JL, Dimsdale JE (1999) Relationship of arousals from sleep to sympathetic nervous system activity and BP in obstructive sleep apnea. Chest 116:655659. doi:10.1378/chest.116.3.655

26. Rechtshaffen A, Kales A (1968) A manual of standardized terminology, techniques, and scoring system for sleep stages of human subjects. National Institute of Health Publication 204: US Government Printing Office Washington, DC

27. Report ASDA (1992) EEG arousals: scoring rules and examples. Sleep 15:174-184

28. Loredo JS, Clausen JL, Ancoli-Israel S, Dimsdale JE (1999) Night-to-night arousal variability and interscorer reliability of arousal measurements. Sleep 22:916-920

29. Fang J, Wang Y, Krueger JM (1997) Mice lacking the TNF $55 \mathrm{kDa}$ receptor fail to sleep more after TNF-alpha treatment. J Neurosci 17:5949-5955

30. Shearer WT, Reuben JM, Mullington JM, Price NJ, Lee BN, Smith EO, Szuba MP, Van Dongen HP, Dinges DF (2001) Soluble TNF-alpha receptor 1 and IL-6 plasma levels in humans subjected to the sleep deprivation model of spaceflight. J Allergy Clin Immunol 107:165-170. doi:10.1067/mai.2001.112270

31. Kataoka T, Enomoto F, Kim R, Yokoi H, Fujimori M, Sakai Y, Ando I, Ichikawa G, Ikeda K (2004) The effect of surgical treatment of obstructive sleep apnea syndrome on the plasma TNF-alpha levels. Tohoku J Exp Med 204:267-272. doi:10.1620/tjem.204.267

32. Phillips CL, Yang Q, Williams A, Roth M, Yee BJ, Hedner JA, Berend N, Grunstein RR (2007) The effect of short-term withdrawal from continuous positive airway pressure therapy on sympathetic activity and markers of vascular inflammation in subjects with obstructive sleep apnoea. J Sleep Res 16:217-225. doi:10.1111/j.1365-2869.2007.00589.x

33. Alberti A, Sarchielli P, Gallinella E et al (2003) Plasma cytokine levels in patients with obstructive sleep apnea syndrome: a preliminary study. J Sleep Res 12:305-311

34. Kobayashi K, Nishimura Y, Shimada T, Yoshimura S, Funada Y, Satouchi M, Yokoyama M (2006) Effect of continuous positive airway pressure on soluble CD40 ligand in patients with obstructive sleep apnea syndrome. Chest 129:632-637. doi:10.1378/chest.129.3.632

35. Ryan S, Taylor CT, McNicholas WT (2005) Selective activation of inflammatory pathways by intermittent hypoxia in obstructive sleep apnea syndrome. Circulation 112:2660-2667. doi:10.1161/ CIRCULATIONAHA.105.556746

36. Dickstein JB, Moldofsky H, Lue FA, Hay JB (1999) Intracerebroventricular injection of TNF-alpha promotes sleep and is recovered in cervical lymph. Am J Physiol 276:R1018-R1022 